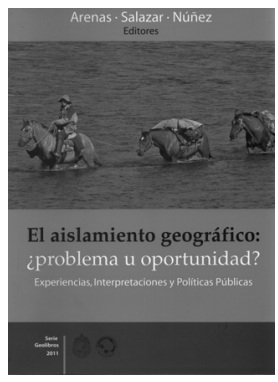

\title{
Federico Arenas, Alejandro Salazar y Andrés Núñez (editores). El aislamiento geográfico: ¿problema u oportunidad? Experiencias, interpretaciones y políticas públicas
}

\author{
Santiago de Chile: Serie Geolibros No 15, Instituto de Geografía, \\ Pontificia Universidad Católica de Chile, 2011. 253 p.
}

\author{
Macarena Pérez García
}

La comprensión del aislamiento desde una perspectiva no solo física, sino que también desde una lectura de la geografía social, ambiental y/o cultural, es el eje central sobre el que se desarrollan las distintas visiones de esta obra.

Las preguntas que guían los enfoques planteados por los autores se desenvuelven entre la idea del aislamiento como un problema, pero que a la vez puede ser considerado una oportunidad. La percepción de los mismos habitantes de ciertos territorios de Chile resulta en este caso primordial, para afirmar que desde una perspectiva personal no existiría una conciencia real de la condición de aislamiento, al menos al no sentirse aislados en términos físicos, sino que más bien desde un punto de vista político y referido a la toma de decisiones.

El comprender el aislamiento como sinónimo de separación e incomunicación se relativiza a través de las investigaciones presentadas en el texto, que muestran cómo este concepto al igual que la definición de frontera se resignifica en el tiempo. A través de los tres apartados del libro es posible discutir sobre distintas miradas en torno al aislamiento, entendiendo esta condición no solo como un problema, sino que al

\footnotetext{
1 Pontificia Universidad Católica de Chile (Chile). E-mail: mperez1@uc.cl
}

desarrollar actividades como el turismo u otras pudiera ser también un oportunidad de rescatar las identidades territoriales que se forjan en condiciones muchas veces desfavorables desde el punto de vista de accesibilidad y comunicaciones.

El libro se estructura en tres apartados. El primero de ellos referente a las experiencias, rescata desde distintas miradas la forma de entender el aislamiento. En los textos que componen esta sección se abordan en primer lugar las perspectivas para el territorio de Aysén, en la Patagonia Chilena, en comparación con islas costeras francesas (íles du Ponant). A partir de la investigación que origina el artículo, el aislamiento en el que se encontraría un "isla" pasa a ser similar al de condiciones de montaña, oasis u otro tipo de asentamiento.

Una segunda mirada sobre la situación de aislamiento geográfico de la comuna de Tortel, Región de Aysén, nos acerca hacia la perspectiva desde lo local, dando importancia a los elementos identitarios de los habitantes de este territorio, en ocasiones incomunicada. Cómo se integra esta zona a un sistema globalizado sin perder la esencia que lo hace particular, resulta ser el mayor desafío de sus habitantes de acuerdo a lo expresado por el su alcalde, Sr. Bernardo López Sierra.

Dos artículos siguientes permiten situarse en la realidad actual e histórica del norte 
de Chile en cuanto a la condición de aislamiento. El artículo elaborado por Camus y Rosenblitt aborda la perspectiva histórica que generó la incorporación de territorios al Estado-Nación chileno y su consecuente desarrollo a través de las políticas emprendidas que buscaban potenciar la industrialización y la defensa nacional, para las ciudades de Arica e Iquique.

Mediante los circuitos turísticos patrimoniales de las Rutas de las Misiones en la precordillera de Arica-Parinacota, se plantea la posibilidad de realizar un turismo que sea capaz de incorporar estos territorios rescatando como un valor el hecho de ser considerados paisajes aislados. El atractivo de los imaginarios coloniales e iglesias en lugares remotos y de difícil acceso es justamente lo que se valoriza por un público que va más allá de la propaganda de acuerdo a los autores Pablo Osses y Cristian Heisen.

Una mirada hacia el pasado, mediante los apuntes de bitácora realizados por el geógrafo austríaco Axel Borsdorf en su recorrido por Aysén en 1979, permiten reconstruir la condición de aislamiento geográfico de esos territorios, con niveles de comunicación precarios y un poblamiento bastante incipiente.

Algunas interpretaciones en torno al aislamiento geográfico y sus alcances a distintas escalas y condiciones se abordan en el segundo apartado del libro. Desde las observaciones captadas en el marco del proyecto que origina el presente libro se obtienen interesantes miradas locales sobre el tema, expresando más bien un sentir de aislamiento sobre la toma de decisiones y la determinación de políticas más que una condición dada por la localización.

Resulta clarificador para la comprensión sobre cómo se ha entendido el aislamiento a través de la historia chilena el texto de Núñez. La interrogante que guía sus reflexiones intenta responder a si es posible hablar sobre los conceptos de aislamiento y frontera sin mirar hacia el movimiento temporal que las definiciones de estos han tenido, que no resulta ser estática ni definitiva, muy por el contrario, es tan dinámica como los imaginarios de sus habitantes.
El concepto de geodiversidad, muy poco abordado en Chile y su relación con el aislamiento son trabajados en el texto de Esteban Delgado. El gran potencial que albergarían áreas denominadas como aisladas en cuanto a su patrimonio, visto desde la geodiversidad, permitiría una revalorización de estos territorios, no sin antes enfrentarse al desafío de la comprensión del aislamiento desde una perspectiva positiva por sobre la negativa y una necesidad de empaparse de ciertas realidades locales que por ahora son vistas desde la lejanía.

Dadas las circunstancias actuales de Chile, sobre los conflictos limítrofes con países vecinos, resulta interesante la mirada propuesta por los arquitectos Corvalán, Loyola y Retamal. En el texto se expresa la oportunidad que representaría una nueva configuración político-territorial de Chile, Perú y Bolivia, que desde una perspectiva de conectividad podría considerarse aislados al no funcionar en conjunto en temas de desarrollo y soberanía.

Los subterritorios, nombre que recibirían para Buscaglia los territorios aislados, son el eje central del texto que mira el aislamiento más allá del contexto geográfico. El autor formula el asunto desde un punto de vista que rescata la particularidad de los habitantes, la necesidad de potenciar las identidades locales. El generar organizaciones de base para estas zonas con características únicas que han favorecido en gran medida la asociatividad, permitiría un desarrollo desde adentro y por tanto la aplicación de instrumentos no centralistas.

Un último artículo de este segundo apartado, desarrollado por Carla Marchant y Rafael Sánchez, aborda los imaginarios relacionados con la montaña en Chile. Se expresa en el texto cómo la cordillera de los Andes, a pesar de formar parte del territorio reconocido a lo largo del país, constituye un espacio aislado, olvidado y marginal.

Las temáticas relacionadas con las políticas públicas asociadas a los territorios aislados se abordan en una tercera sección del libro. La postura expresada por la ministra de Bienes Nacionales, Catalina Parot, da cuenta de la necesidad de un ordenamiento 
del territorio que sea capaz de visualizar las diferencias de este, dando el valor que corresponda en este caso a la propiedad fiscal. Dicha propiedad podría ser vista como una oportunidad de hacer gestión al incorporarlos al desarrollo del país con una mirada global.

Los lineamientos actuales en cuanto al desarrollo de localidades aisladas por parte de la Subsecretaria de Desarrollo Regional (SUBDERE) son abordados por Miguel Flores. En el texto se expresan las iniciativas realizadas por la autoridad en esta materia y se plantean medidas a futuro para estas zonas.

\section{Reflexiones finales}

El aporte del libro a la comprensión del aislamiento desde distintas perspectivas cobra relevancia, hoy más que nunca, en el panorama del territorio chileno.

La ciudadanía en distintas regiones de Chile, que pudiesen ser consideradas en una situación de aislamiento desde alguna de las visiones expuestas, ha manifestado su posición frente a demandas que han aguardado años por una solución. Las condiciones de insatisfacción en aspectos tan relevantes como la salud y educación dan muestra del descontento frente a la situación de incomunicación y sobre la toma de decisiones políticas.

Quizás uno de los ejes del texto, que plantea justamente al aislamiento como una oportunidad, se ve reforzado por este sentir social, al igual que el potencial de asociatividad entre los habitantes de zonas en que el diario vivir se dificulta frente a las condiciones físicas y políticas adversas.

Desde la "topofilia" planteada por Yi Fu Tuan, entendida como el lazo afectivo entre las personas y el territorio en el que habitan, es posible explicar el apego de los habitantes de territorios en ocasiones hostiles como la Patagonia chilena, a los paisajes que han marcado su diario vivir. La oportunidad radicaría entonces en potenciar este sentimiento mediante la gestión a nivel local para lograr el desarrollo de proyectos asociados a la identidad, que rescaten estos elementos sobre todo al momento de definir políticas, planes y programas que pretendan responder en alguna medida a las demandas sociales. No en vano, cerca de un $80 \%$ de un amplio universo de entrevistados en valles aislados de la Región de Aysén opinó que ellos no se sentían físicamente aislados, valorizando su espacio original, sino que su aislamiento era más bien político o social. El punto es muy relevante, ya que las políticas públicas en torno al aislamiento se originan desde las ciudades y desde los centros de poder, proyectando sus miedos y anhelos, con muy poca, sino nula, participación de la ciudadanía local.

El aislamiento, por consiguiente, debe ser comprendido desde varias miradas, si lo que se pretende lograr es conservar y resaltar elementos identitarios que harían únicos a estos espacios y de la misma forma orientar políticas de desarrollo. La concepción de aislamiento geográfico puede, ser por tanto complementada con los elementos que componen el territorio, y vista desde el sistema territorial que abarca aspectos físicos y sociales, el espacio geográfico "aislado" requiere por tanto una mirada sistémica.

\section{Referencias bibliográficas}

TUAN, Y. F. Topofilia. Un estudio de las percepciones, actitudes y valores sobre el entorno. Madrid: Melusina, 2007. 
